\title{
A Study on Cultural Difference between Korea and the U.S. that the Korean Women who Married American Men Feel
}

\author{
Mijung Lee ${ }^{1}$, Youngsoon $\mathrm{Kim}^{2}$, Hyekyeong $\mathrm{Nam}^{3}$ and Heejin Yun ${ }^{4}$ \\ ${ }^{1,2,3,4}$ Department. of Multicultural Education, Inha University \\ 1'pro03@hanmail.net, ${ }^{2}$ kimysoon@inha.ac.kr, ${ }_{4}^{3}$ ssalguaja@naver.com, \\ ${ }^{4}$ culturejin@naver.com
}

\begin{abstract}
This study is focused on researching how the Korean women who married American men recognize the cultural differences and discovering their sentiment between Korea and U.S. For this purpose, in-depth interview is conducted with six Korean women who married American men. The result of this research is classified as visible and invisible level of culture. The reorganization of visible cultural differences is shown that they are departed from main society and built their own community because of food and language differences. By the contrast, invisible level indicates that there are cultural differences in common behavior and attitude. In the other words, for example, a desire to help others is recognized in different ways in Korea and U.S., which can be an uncomfortable obligation or service opportunity. In addition, their attitude that brings leisure differences is the reason why the Korean women who married American men keep their own community in the U.S. Lastly, they express their feelings about gaps in two different cultures as empty seats or the lost home, however, they refuse to return back to Korea because they assume that their children will bring the same results as they have.
\end{abstract}

Keywords: Korean women who married American men in the U.S., Cultural adjustment, Language, Prejudice, Individualism

\section{Introduction}

Korean women who left Korean traditional culture and customs through international marriage suffer from a conflict in values in talking to their husband and children in a special situation of biculture and experience the crisis of identity that they neither fully belong to Korea society nor American society [1]. In addition, the Korean women who married foreign men have low self-esteem as a collective trend. In addition, they have differences in language, food and mindset and Korean women find themselves to be outsiders [5]. There are two cultural differences between Korean consciousness of rank by age and American consciousness of equality and between Korean collective consciousness and American individualism [2]. In addition, as for the background of the sayings and proverbs, there are a number of fables about tigers and rabbits in Korea while American fables have a Christian background. Korea and the U.S. have different physical spaces, history, language, meaning, consciousness and culturally different characteristics. The preceding studies show that the Korean women who married American men may face various difficulties due to the cultural

Article history:

Received (September 26, 2016), Review Result (November 27, 2016), Accepted (December 19, 2016) 
differences between Korea and the U.S. in American society. This study investigated the differences in cultures and emotions between Korea and the U.S. in Korean women who married American men and moved to the U.S. in the 1990s. The expected effects of this study are that first, it would be a means to broaden Korean people's concern and understanding the Korean women who married American men. Second, it is expected that this study will contribute to examining and gaining an insight into Korea's current reality of multicultural society in various ways. Accordingly, research questions are as follows:

First, what is the experience of cultural difference between Korea and the United States?

Second, what is the emotion because of cultural difference in Korean women who married American men?

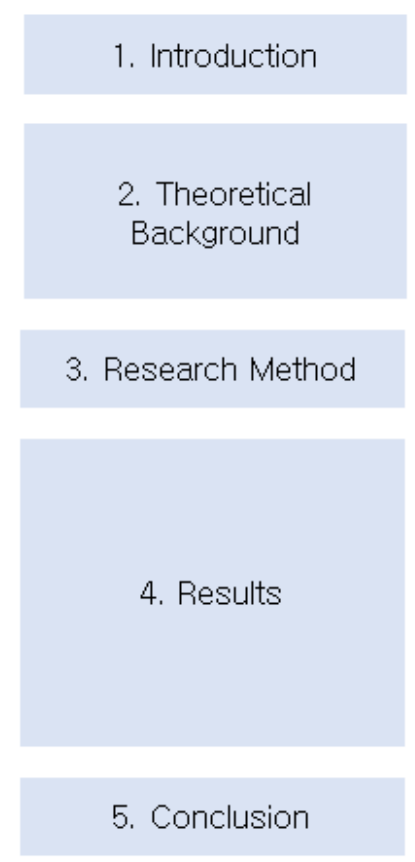

Background and purpose of a research

2.1. National Culture: Korea \& U.S.A.

2.2. Characteristics of Korean women married American men

in-depth interview, 6 Korean immigrant women

4.1 Cultural differences between Korea and the U.S.A.

Visible dimension of culture Invisible dimension of culture

4.2 Emotions Korean women feel in American society

missing of their hometown, looking for the food imprinted on their appetite

Figure1. Research flow

\section{Status and characteristics of Korean women married American men}

To look at the 2007-2015 Status of International Marriage of the National Statistics Office (2016), the number of marriages between Korean women and foreign men gradually decreases, repeating increase and decrease at a narrow difference [8]. The number of couples married to Chinese and Japanese men was 1,052 in 2015, which decreased from 2,541 in 2007 while the number of international marriages to American men increased by 278 couples, which is a much higher than increases, respectively, by 111 and 96 couples of international marriage to Canada and Australia. Like this, international marriage steadily continues, but there are only a few studies of these Korean women who married American men. The Korean women who married American men in the preceding studies live with a conflict of identity, personally, and in the relationship with their children, they have difficulties in communication because of the characteristics of bicultural in their family, perceptional gap and communication problems from cultural difference, and they experience a difference in values 
with their children. In addition, because of physical cultural characteristics, they become the subjects of discrimination in the society they settle down and are in an alienated position in their own family, e.g. They cannot discuss with their parents who objected to their marriage at ease when there is a conflict in their married life. Park, Hae-gwang (2015) noted that the Korean women who married American men form their inherent identity, which is not completely taken into the order of American spouse and it is defined as 'living in the U.S.,' not 'becoming American people' in American society [1]. They are enthusiastic about looking for Korean food ingredients and want to maintain their identity as Korean people even if they have lived for 30 years. Yang, Jeong-hae (2000) noted that the Korean women who married American men gather, organizing their own meeting and that they sign up and attend the meeting because they feel lonely in their life in the U.S. and they would like to get along with Korean people [7]. In addition, they are very sensitive to the view of others in the Korean society (Korean Immigrants Association) on them and have low self-esteem because of the negative view on international marriage that has continuously existed in Korean society.

Anthropologists say that people belonging to each human society show big differences in the ways to experience, express and understand emotions. Cultural differences act greatly in the ways by which people think about the emotions and look for meanings. For example, even if they are from the same ethnic group, people with a different cultural background have slightly different facial expressions [5][6]. In a study of emotions in Korea and the U.S., Choi, Geung-ho (1997) noted that care for others can be rated high in Korean collectivist sentiment and emotion, helpful in pursuing individual autonomy and independence, in American individualist society [3][4].

Like this, there is a difference in the way to express emotions or understand their meanings differ depending on the culture to which an individual belongs, which would affect the individual's adjustment to the culture and society. Supposing that Korea belongs to a collectivist culture while the U.S. belongs to an individualistic culture, it is expected that the emotions of the Korean women who married American men, adjusting themselves to American society cannot but be directly and indirectly affected from cultural difference, significantly. Accordingly, this study would examine the cultural difference between Korea and the U.S., perceived by them and look for their individual emotions in American society.

\section{Research method}

Interviews for this study of the differences in cultures and emotions between Korea and the U.S., perceived by the Korean women who married American men were conducted from early July 2016 to late August 2016, and before the interviews, research ethics and taperecording were explained and interview dates were set up after receiving an agreement. The number of times was one time to three times by the participant, and the interviews were carried out through the Internet. 


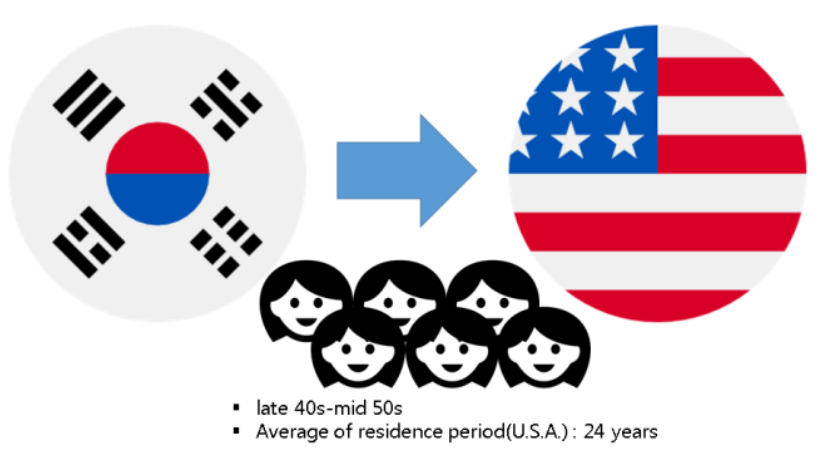

Figure2. Research method

\section{The results}

\subsection{Cultural differences between Korea and the U.S.}

The research participants' recognition about cultural differences would be classified into a visible dimension, including man-made cultural products such as food, clothing and language and an invisible dimension, such as value, code of conduct, attitude and social role.

\subsubsection{Visible dimension of culture: Food and language}

The research participants say that they had difficulty in sticking to Korea's unique dietary culture while living in the U.S. even if they wanted to eat Korean food. They said that in an earlier period after they moved to the U.S., they had a difficulty that they must eat Korean food, but now, it became no problem. Some adjusted themselves to their reality, having no choice but to change their Korean life, and some could not help eating Korean food, no matter how hard they tried to adjust themselves to the reality of American food.

The research participants commonly say that they suffered from difficulties because of a lack of language skills in an early stage of their study. However, as time passed, they became accustomed to communication in work life or social organization life, so that they did not have any problem with that, but it had been quite a hard process to do so. In particular, talking about limitations in conversing in English, Research Participant 3 said that Korean language has various vocabularies to express diverse feelings but English does not. It is not known here that, since one language has fewer expressions with feelings than another language, the members of the society speaking the language share fewer feelings. However, because of different languages, even if they talk about the same feelings and the same things, their mind is not received, probably because of the time, history and cultural difference not shared by individuals belonging to two cultures.

\subsubsection{Invisible dimension of culture: Code of conduct (Mutual aid and donation) and Attitude (Entertainment culture)}

Since Korean people feel so lonely in their life in a foreign country, they open their heart and often get hurt or fraud. They have different propensities for play, so it is not easy for the two groups to gather together and get along with each other. The research participants say that accordingly, American immigrants gather by their ethnic group as a unit and enjoy play 
culture. Socially weak groups that enjoy play culture separately may sometimes get along together, but the research participants talk about the case in which the groups stay apart since they have different cultural propensities.

Since Korean people feel so lonely in their life in a foreign country, they open their heart and often get hurt or fraud. They have different propensities for play, so it is not easy for the two groups to gather together and get along with each other. The research participants say that accordingly, American immigrants gather by their ethnic group as a unit and enjoy play culture. Socially weak groups that enjoy play culture separately may sometimes get along together, but the research participants talk about the case in which the groups stay apart since they have different cultural propensities.

\subsection{Emotions Korean women feel in American society}

According to anthropologists, people belonging to different cultures have big differences in the ways to experience, express and understand emotions, and cultural difference act greatly in the ways for people to think about emotions and look for meanings. Therefore, this study examined the emotions of the Korean women that married American men, who grew up in Korean culture in American culture and society.

\section{The results}

This study is research on the cultural difference between Korea and the U.S. perceived by Korean women who married American men and their current emotions. As a result of the study, a culture was classified into visible dimension and invisible dimension, and in the visible dimension, this study discussed the experience of differences in food and language while in invisible dimension, it discussed the experience of cultural differences in the code of conduct and attitude. The code of conduct was classified as Korean culture of mutual aid and American culture of donation, and culture concerning how to play or use spare time.

The cultural differences in language and food appearing in the visible dimension of culture are as follows: The research participants responded that they have Korean food about 3 times a week and they eat Korean food alone even if other family members have American food. In language, they do not have difficulty in communication, but they see and exchange Korean people, away from the mainstream American society, not being able to understand the history and culture in the language. In the invisible cultural difference, in American culture with strong individualism in which people do not care for others more than necessary, there is a clash against Korean culture in which people care about others and prefer getting along together. Related to this, Korean women gather and promote friendship with other Korean women rather than getting along with American women. Cultural differences showed that it seems that the Korean women who married American men seem to be well adapted to American society on the surface, but they are separated from the society and may make regionalism among Korean people. In addition, the emotions of the Korean women because of these cultural differences include emptiness, loneliness, nostalgia and loss of hometown.

In addition, they said that they could not return to Korea since they already had life in the U.S., had burden to set up a new base and would not make their children people who lost their hometown. These people live a stable life in the U.S. and do not consider their life there a life they should regret or undo. However, the emotions they feel included missing of their hometown, looking for the food imprinted on their appetite, history melted in their language and separation from by the difference in time with American society and its members. 


\section{Acknowledgements}

This work was supported by the Ministry of Education of the Republic of Korea and the National Research Foundation of Korea (NRF-2015S1A5A2A03048350)

\section{References}

[1] E.Y. Woo, "A study on overcoming the identity-crisis of intercultural marriage couples - focused on korean middle age women who married American men," The Bible and Consultation. vol.6, pp.132-157 (2000)

[2] S.H. Lee, "A study on communication difficulties caused by verbal and nonverbal cultural differences: with a focus on cultural differences between Korea and America," English Studies, vol.38, no.2, pp.271-288, (2012)

[3] G.H. Choi, "Cultural variations in emotions: public sentiment for the understanding of korean people's emotions," Psychological Science, vol.6, no.2, pp.1-43

[4] M.J. Lee and M.S. Park, "Case study on types of conflict multicultural adolescents experience," Journal of Education \& Culture, vol.20, no.3, pp.149-177, (2014)

[5] G.H. Min, O.K. Lee, J.I. Lee, M.H. Kim, S.M. Jang, and M.C. Kim, "Emotion psychology (original: J.W. Kalt., M.N. Shicta. Emotion)," Cengage Learning, (2007)

[6] M.K. Kim, "Comparative study on stress that mothers with infants have in raising them: Focused on native and immigrant mothers," Graduate School of Sungkyul University, (2009)

[7] J.H. Yang, "Use of media of Korean women in the U.S.: Focused on the use of Korean Videos of Korean Women who married American Men," Collection of Papers for Korean Association for Broadcasting \& Telecommunication Studies Symposium, Korea, pp.22-31, (2000)

[8] National Statistics Office, “Annual report on the international marriage statistics,” Korea, July 22, (2016) 


\section{Authors}

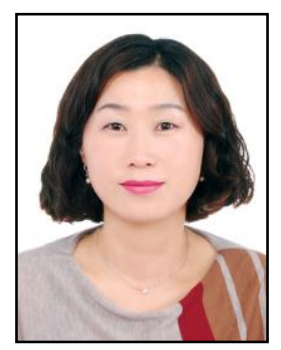

\section{Mijung Lee}

Ph.D. in Culture Management

Teaching Professor in Dept. of. Multicultural Education, Inha

University

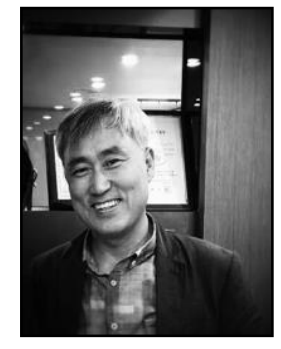

Youngsoon Kim, Ph.D.

Dean, Graduate School of Education

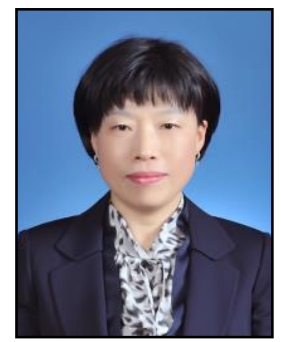

\section{Hyekyeong Nam}

Master of Education

Researcher in Dept. of. Multicultural Education, Inha University

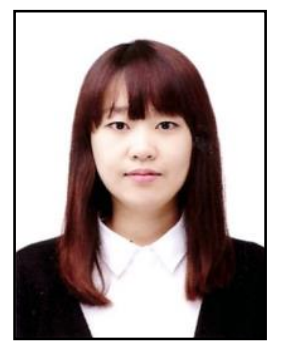

\section{Heejin Yun}

Ph.D. in Culture Management

Research Professor in Center for Glocal Multicultural Education

Professional Development, Inha University 
A Study on Cultural Difference between Korea and the U.S. that the Korean Women who married American Men Feel

This page is empty by intention. 